\title{
Corrosion and tribocorrosion behaviour of Ti6Al4V produced by selective laser melting and hot pressing in comparison with the commercial alloy
}

\author{
Fatih Toptan $^{\mathrm{a}, \mathrm{b}, \mathrm{c}, *}$, Alexandra C. Alves ${ }^{\mathrm{a}}$, Óscar Carvalho ${ }^{\mathrm{a}, \mathrm{b}}$, Flávio Bartolomeu ${ }^{\mathrm{a}}$, Ana M.P. Pinto ${ }^{\mathrm{a}, \mathrm{b}}$, \\ Filipe Silva ${ }^{\mathrm{a}, \mathrm{b}}$, Georgina Miranda ${ }^{\mathrm{a}, \mathrm{b}}$ \\ ${ }^{a}$ CMEMS-UMinho - Center for MicroElectroMechanical Systems, Universidade do Minho, Azurém, 4800-058, Guimarães, Portugal \\ ${ }^{\mathrm{b}}$ Universidade do Minho, Dept. Eng. Mecânica, Azurém, 4800-058, Guimarães, Portugal \\ ${ }^{\mathrm{c}}$ IBTN/Br - Brazilian Branch of the Institute of Biomaterials, Tribocorrosion and Nanomedicine, UNESP, Campus de Bauru, Av. Eng. Luiz Edmundo Carrijo Coube, 14-01, \\ 17033-360, Bauru, SP, Brazil
}

\section{A R T I C L E I N F O}

Associate Editor: A. Clare

Keywords:

Corrosion

hot pressing

selective laser melting

Ti6Al4V

tribocorrosion

\begin{abstract}
A B S T R A C T
The corrosion and tribocorrosion behaviour of SLM-produced Ti6Al4V alloy was studied in comparison with its $\mathrm{HP}$ and commercial counterparts in $9 \mathrm{~g} / \mathrm{L} \mathrm{NaCl}$ solution at body temperature. Results showed that SLM processing route influenced the electrochemical response of the SLM-produced alloy by leading to a relatively lower quality for the passive film due to decreased $\beta$ phase and the formation of $\alpha^{\prime}$ phase. However, after tribocorrosion, neither the total volume loss nor the volume loss under the influence of mechanical wear and wearaccelerated corrosion showed any statistically significant difference between the processing routes.
\end{abstract}

\section{Introduction}

Ti6Al4V is the most popular Ti alloy in various engineering applications, including dental and orthopaedic implants, owing to its attractive corrosion resistance and decent mechanical stability. As reviewed by Zhang and Attar (2016), Ti alloys are usually being processed by conventional techniques such as solidification or powder metallurgy $(\mathrm{P} / \mathrm{M})$ based routes however, high reactivity of Ti, its high affinity to oxygen, and difficulties on obtaining near-net shape products are some of the typical challenges on solidification routes. It is wellknown that P/M-based techniques offer some advantages over casting such as eliminating uncontrolled porosity, chemical inhomogeneity, and grain growth. Bolzoni et al. (2012) showed that hot pressing (HP) offers better properties than the conventional $\mathrm{P} / \mathrm{M}$ route, along with its advantage on providing a simpler fabrication process even for relatively complex shapes.

As stated by Zhang and Attar (2016), selective laser melting (SLM) is an emerging additive manufacturing (AM) technique that can be easily applied to the complex structures, giving properties equivalent or superior than the ones processed by conventional routes. Vrancken et al. (2012) stated that fast and localized melting and fast cooling leads to thermal gradients during processing which eventually leads to thermal stresses, segregation, and occurrence of non-equilibrium phases. Consequently, SLM-produced materials typically present very fine, non- equilibrium structures, such as acicular martensitic structure $\left(\alpha^{\prime}\right)$ as reported by Kasperovich and Hausmann (2015) and Thijs et al. (2010) for Ti6Al4V alloy.

As pointed by Attar et al. (2015) and Zhang and Attar (2016), studies on AM Ti6Al4V alloy were mainly concentrated on microstructure and mechanical properties, whereas the studies on wear and corrosion behaviour are relatively scarce. Attar et al. (2015) explored the dry sliding wear behaviour of SLM-produced commercially pure titanium (CP-Ti) in comparison with its cast counterpart and observed similar wear mechanisms on both SLM and cast samples after testing against hard-faced stainless steel discs under 15, 20, 25, and $30 \mathrm{~N}$ loads, $0.5 \mathrm{~m} /$ $\mathrm{s}$ sliding speed during $15 \mathrm{~min}$. Even though, the authors reported that SLM-produced CP-Ti exhibited better wear resistance and attributed this behaviour to its microstructure having $\alpha^{\prime}$ phase and finer grains. Toh et al. (2016) investigated the dry sliding wear behaviour of Ti6Al4V alloy produced by electron beam melting (EBM), that is a similar technique to SLM, by testing against a $6 \mathrm{~mm}$ diameter of $100 \mathrm{Cr} 6$ steel ball under $1 \mathrm{~N}$ normal load, $2 \mathrm{~cm} / \mathrm{s}$ sliding speed during 50000 cycles, where as-cast Ti6Al4V alloy was used as a control group. Although similar wear characteristics were observed on the samples produced by two different techniques, EBM-produced samples presented higher wear resistance.

Dai et al. (2016) investigated the corrosion behaviour of SLM-produced Ti6Al4V in comparison with its commercial (grade 5)

\footnotetext{
* Corresponding author.

E-mail address: ftoptan@dem.uminho.pt (F. Toptan).
} 
counterpart and reported inferior behaviour for the SLM-produced alloy in $3.5 \mathrm{wt} . \% \mathrm{NaCl}$ solution. The authors stated that the corrosion behaviour was influenced by the microstructure of the SLM-produced alloy which was dominantly composed of acicular $\alpha^{\prime}$ martensite phase, leading to a non-equilibrium microstructure. De Damborenea et al. (2017) investigated the electrochemical behaviour of Ti6Al4V alloy produced by direct metal laser sintering (DMLS) where also the martensitic transformation of $\beta$-phase was reported due to the rapid quenching. The authors performed potentiodynamic polarization tests in phosphate buffered saline solution (PBS) in comparison with the commercial Kirschner wire of Ti6Al4V and reported that although there was no significant difference on corrosion kinetics, processing defects such as surface porosity acted as crevices and led to localized corrosion on those sites. On the other hand, Amaya-Vazquez et al. (2012) studied the influence of laser remelting to the electrochemical response of Ti6Al4V in $3.5 \mathrm{wt} . \% \mathrm{NaCl}$ solution and stated that the martensitic microstructure on laser remelted Ti6Al4V samples exhibited increased corrosion resistance that was attributed by the authors to the development of $\alpha^{\prime}$ martensitic microstructure.

It is known that the synergistic interactions between corrosion and wear usually result in increased material loss as compared to the individual wear or corrosion actions. Thus, since biomedical implant materials subject to relative movements in the corrosive body environment, the synergistic or antagonistic interplays between wear and corrosion needs to be understood. Therefore, the aim of this work was to study the corrosion and tribocorrosion behaviour of SLM-produced Ti6Al4V alloy in comparison with its hot pressed and commercial counterparts, as well, to have a preliminary look on the synergistic interactions between corrosion and wear.

\section{Experimental procedure}

\subsection{Materials and processing}

Spherical powders with $20-50 \mu \mathrm{m}$ mean size (SLM Solutions, Germany) were used for processing HP and SLM Ti6Al4V samples, whereas commercial cast and forged Ti6Al4V alloy (Bunting Titanium, UK) was used as control group (CM). According to the suppliers' datasheet, the chemical composition (in wt.) of the bulk (cast and forged) alloy was $6.4 \% \mathrm{Al}, 3.8 \% \mathrm{~V}, 0.01 \% \mathrm{C}, 0.23 \% \mathrm{Fe}, 0.12 \% \mathrm{O}, 0.02 \% \mathrm{~N}$, $0.0074 \% \mathrm{H}$, balanced by $\mathrm{Ti}$, whereas the composition of the powder was $6.1 \% \mathrm{Al}, 4.21 \% \mathrm{~V}, 0.2 \% \mathrm{Fe}, 0.003 \% \mathrm{Sn}, 0.03 \% \mathrm{Ni}$, balanced by $\mathrm{Ti}$.

HP-Ti6Al4V samples were processed under $10^{-2} \mathrm{mBar}$ vacuum and $44 \mathrm{MPa}$ pressure at $1175^{\circ} \mathrm{C}$ for $30 \mathrm{~min}$. SLM-Ti6Al4V samples were processed by $\mathrm{Yb}$-Faser-Laser having $87 \mu \mathrm{m}$ spot (SLM Solutions, $125 \mathrm{HL}$ ) under an inert gas mixture of $\mathrm{Ar}$ and $\mathrm{N}_{2}$ where the platform base was kept at $200^{\circ} \mathrm{C}$. SLM processing parameters were selected based on the previous study of Bartolomeu et al. (2016) where the most effective processing parameters were defined as $90 \mathrm{~W}$ laser power, $600 \mathrm{~mm} / \mathrm{s}$ scan speed, $0.08 \mathrm{~mm}$ scan spacing, and $0.03 \mathrm{~mm}$ layer thickness.

After processing, samples were grinded with $\mathrm{SiC}$ papers down to 4000 mesh size, polished with diamond paste $(1 \mu \mathrm{m})$, and etched with Kroll's reagent $\left(5 \% \mathrm{HNO}_{3}, 10 \% \mathrm{HF}\right.$ and $85 \%$ of distilled water) for the microstructural investigations.

\subsection{Corrosion tests}

Sample surfaces were prepared for the corrosion tests by polishing with colloidal silica suspension $(0.04 \mu \mathrm{m}$, Struers OP-S), cleaning in an ultrasonic bath during $10 \mathrm{~min}$ with propanol and $5 \mathrm{~min}$ in distilled water, respectively. Tests were performed in a three-electrode cell having the testing samples having $0.36 \mathrm{~cm}^{2}$ exposed area (working electrode), saturated calomel electrode (reference electrode), and Pt electrode (counter electrode) connected to a Gamry Potentiostat/ Galvanostat/ZRA-Reference 600 (Gamry Instruments, Warminster, PA,

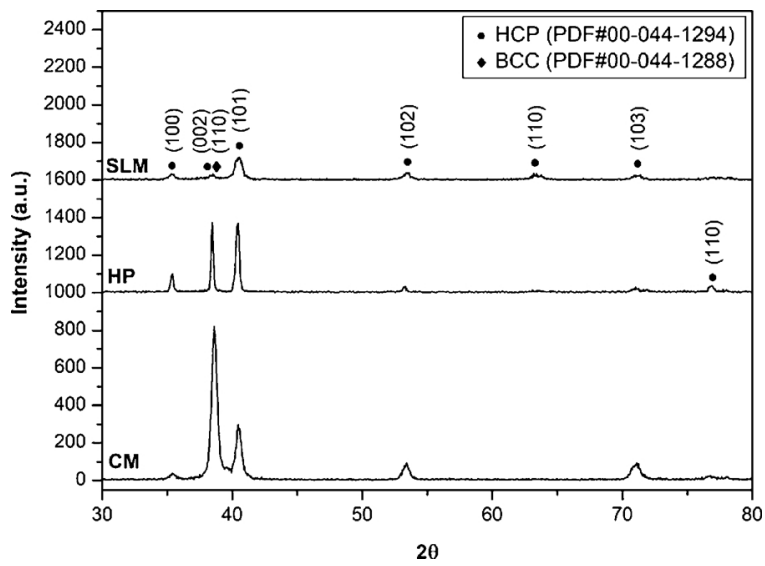

Fig. 1. XRD spectra of testing samples.

USA). As the major compound of the physiological body fluids, $9 \mathrm{~g} / \mathrm{L}$ $\mathrm{NaCl}$ solution $(180 \mathrm{~mL})$ was used as the electrolyte and the temperature of the electrolyte were kept at body temperature $\left(37 \pm 2{ }^{\circ} \mathrm{C}\right)$ by immersing the electrochemical cells into a thermal bath. EIS data acquisition was started after stabilization at open circuit potential (OCP) $(\Delta \mathrm{E}<60 \mathrm{mV} / \mathrm{h}$ ) by scanning frequencies ranged between $100 \mathrm{kHz}$ and $10 \mathrm{mHz}$ with 7 points per frequency decade, and with $10 \mathrm{mV}$ sinusoidal signal amplitude. Then, after waiting $10 \mathrm{~min}$ at OCP, potentiodynamic polarization was applied in a potential range starting $-0.2 \mathrm{~V}_{\mathrm{OCP}}$ to 1 $\mathrm{V}_{\text {SCE }}$ with $0.5 \mathrm{mV} / \mathrm{s}$ scanning rate.

\subsection{Tribocorrosion tests}

Tribocorrosion behaviour was tested on the samples having identical surface conditions to the ones used on the corrosion tests. The samples were mounted in a tribo-electrochemical cell, placed in a heating stage keeping the $30 \mathrm{ml}$ of $9 \mathrm{~g} / \mathrm{L} \mathrm{NaCl}$ electrolyte at body temperature $\left(37 \pm 2{ }^{\circ} \mathrm{C}\right)$. A ball-on-plate tribometer (CETR-UMT-2, CETR/Bruker, USA) was used together with the same three-electrode cell configuration as the static corrosion tests connected to Radiometer PGP201 potentiostat (Radiometer Analytical, Copenhagen, Denmark). Tests were executed under anodic potentiostatic condition to explore the interactions between corrosion and wear. The applied potential value was set as $+0.45 \mathrm{~V}_{\mathrm{SCE}}$ corresponding to the passive zone for all testing groups. After stabilizing the current, sliding was started in a reciprocating movement against an alumina ball having $10 \mathrm{~mm}$ diameter (Ceratec, Geldermalsen, the Netherlands). The tests were performed under $1 \mathrm{~N}$ normal load (420 MPa maximum Hertzian contact pressure) to not to exceed the yield strength of the alloy which is reported by Rooy et al., (1990) within the range of 830-924 MPa for the annealed Ti6Al4V. Sliding frequency was chosen as $1 \mathrm{~Hz}$ and the total stroke length was set as $550 \mu \mathrm{m}$.

One of the approaches being used to quantify the wear-corrosion interactions is so-called mechanistic approach. In this approach, material degradation is assumed to be resulted from two mechanisms, namely (i) mechanical wear, and (ii) wear-accelerated corrosion. According to this approach, the total volume loss after tribocorrosion $\left(V_{t o t}\right)$ is the sum of volume loss due to mechanical wear $\left(V_{\text {mech }}\right)$ and due to wear-accelerated corrosion $\left(V_{\text {chem }}\right)$ (Mischler, 2008):

$V_{\text {tot }}=V_{\text {mech }}+V_{\text {chem }}$

$V_{t o t}$ was calculated using the data acquired from 2D wear track profiles by a non-contact profilometer (Veeco, Dektak 150) and using the approach reported by Doni et al. (2013). $V_{\text {chem }}$ was estimated from Faraday's law:

$V_{\text {chem }}=\frac{Q M}{n F \rho}$ 

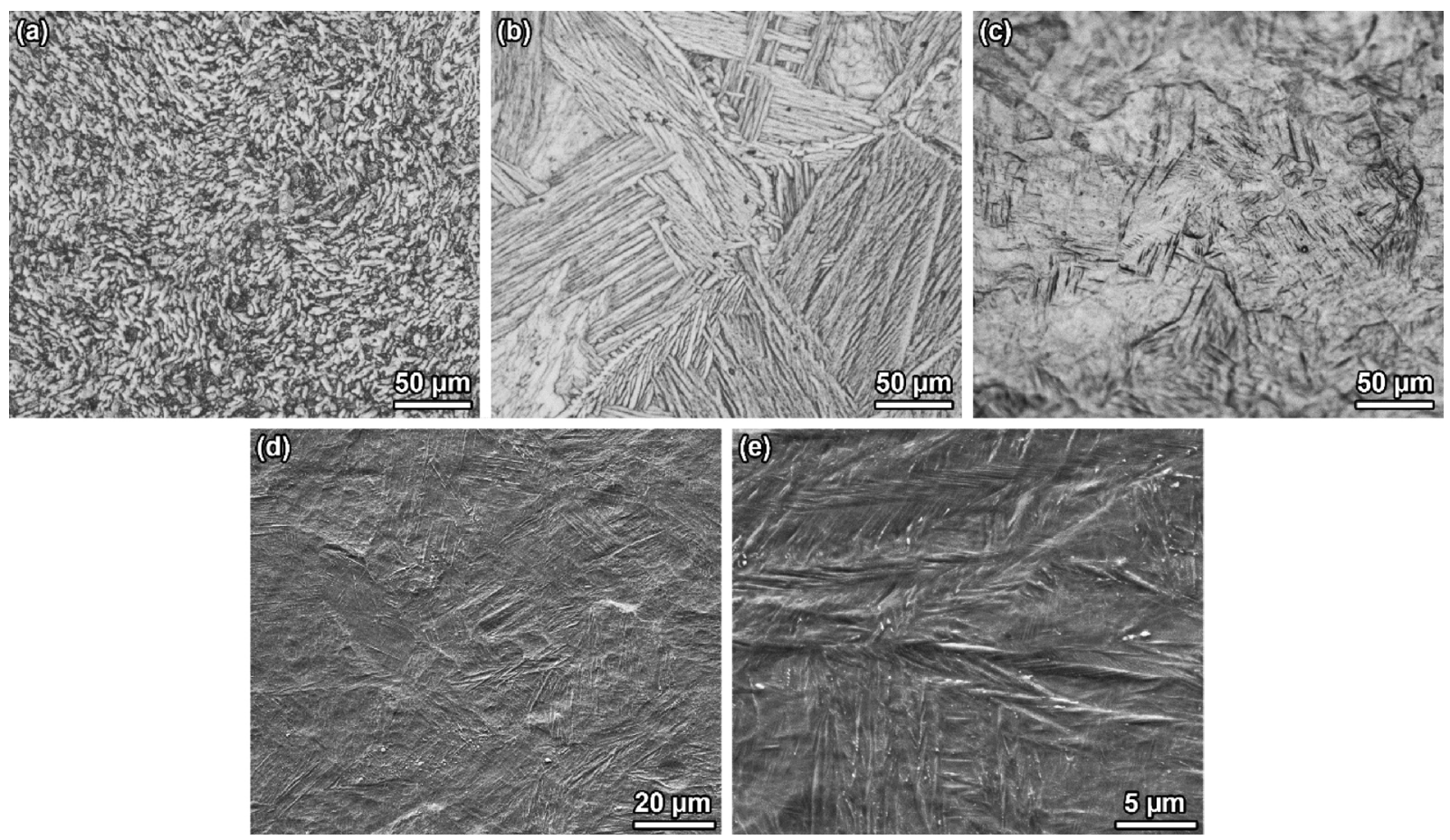

Fig. 2. OM images of a) CM sample showing the finely distributed $\alpha$ and $\beta$ phases, b) HP sample with lamellar microstructure, c) SLM sample containing acicular $\alpha^{\prime}$ phase; d) lower and e) higher magnification SE-SEM images showing the $\alpha^{\prime}$ phase more clearly.
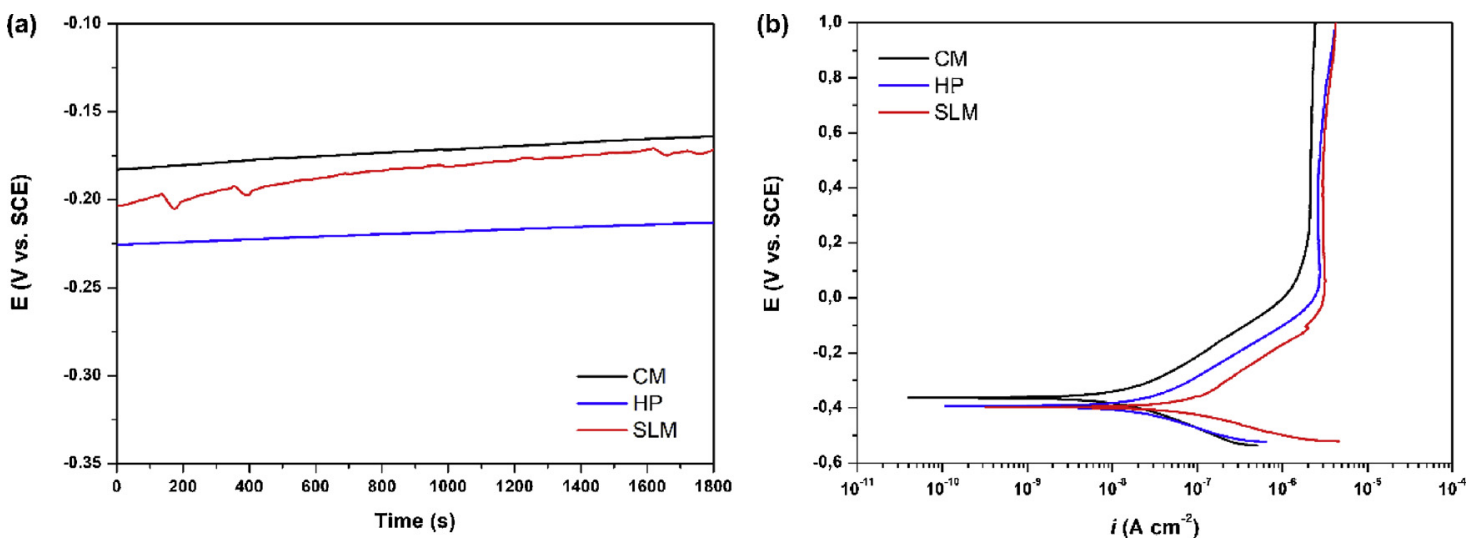

Fig. 3. a) OCP evolution during the last $30 \mathrm{~min}$ of immersion and b) potentiodynamic polarization curves.

Table 1

Open circuit potential $\left(\mathrm{E}_{\mathrm{OCP}}\right)$, corrosion potential $\left(\mathrm{E}_{(i=0)}\right)$ and passivation current density $\left(i_{\text {pass }}\right)$ values.

\begin{tabular}{llll}
\hline Samples & $\mathrm{E}_{\mathrm{OCP}}\left(\mathrm{mV}_{\mathrm{SCE}}\right)$ & $\mathrm{E}_{(i=0)}\left(\mathrm{mV}_{\mathrm{SCE}}\right)$ & $i_{\text {pass }}\left(\mu \mathrm{A} \mathrm{cm}^{-2}\right)$ \\
\hline CM & $-202 \pm 124$ & $-229 \pm 120$ & $2.84 \pm 0.72$ \\
HP & $-202 \pm 105$ & $-289 \pm 182$ & $2.72 \pm 0.67$ \\
SLM & $-205 \pm 146$ & $-301 \pm 107$ & $3.33 \pm 0.14$ \\
\hline
\end{tabular}

where $Q$ is the charge (C), that can be obtained by the integration of the current $(I)$ followed during sliding (Eq. 3), $M$ is the atomic weight of the dissolving element $(\mathrm{g} / \mathrm{mol}), n$ is the dissolution valence, and $F$ is the Faraday's constant $(96490 \mathrm{C} / \mathrm{mol})$. In this study, $\mathrm{M}$ and $n$ values were taken as 47.867 and 4 , respectively, by considering Ti.

$Q=\int_{0}^{t_{\text {sliding }}} I(t) d t$

Finally, after calculating $\left(V_{\text {tot }}\right)$ and $\left(V_{\text {chem }}\right),\left(V_{\text {mech }}\right)$ can be obtained by using Eq. 1.

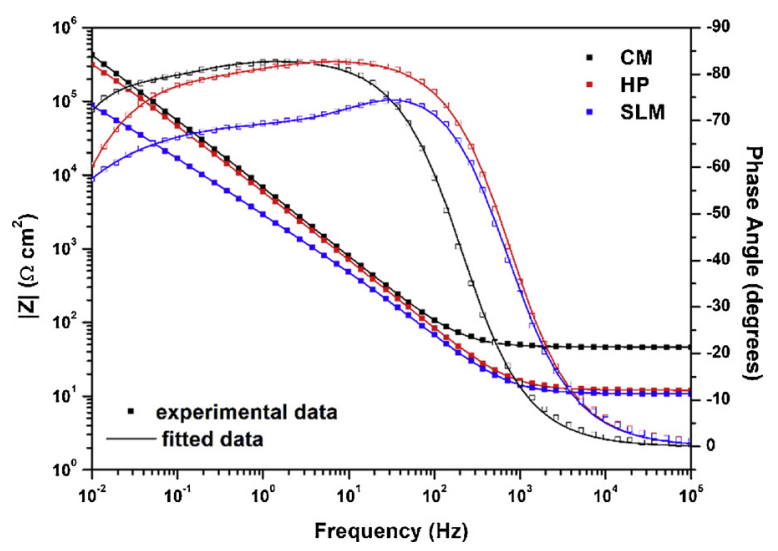

Fig. 4. Bode diagram. 


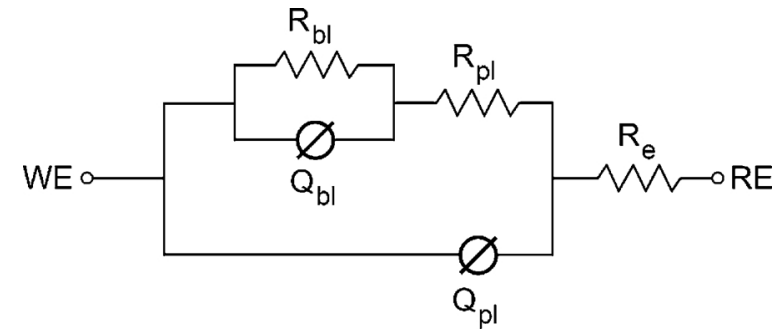

Fig. 5. Electrical equivalent circuit applied for fitting the EIS data.

\subsection{Characterization studies}

Microstructures of the as-processed samples were analysed by optical microscope (OM, Leica DM2500), FEI Nova 200 field emission gun scanning electron microscope (FEG-SEM) with backscattered (BSE) and secondary electron (SE) signals, and EDAX energy dispersive X-ray spectroscopy (EDS). Structural analysis was realized by X-ray diffraction (XRD) with a Bruker D8 Discover diffractometer ( $\mathrm{Cu}$ Ka radiation). Vickers hardness values were obtained using Emcotest Durascan Microhardness tester under $0.3 \mathrm{kgf}$ during $15 \mathrm{~s}$ by obtaining six indentations per group of samples. After corrosion and tribocorrosion tests, samples were ultrasonically cleaned (10 $\mathrm{min}$ in propanol, $5 \mathrm{~min}$ in distilled water), and analysed by FEG-SEM/EDS.

\subsection{Statistical analysis}

Hardness measurements, electrochemical measurements, and tribocorrosion tests were triplicated on different samples and the experimental results were presented as the average \pm standard deviation. The experimental results were analysed by one-way ANOVA followed by Tukey's test for multiple comparisons $(p<0.05)$ by using Origin software (version 8.5).

\section{Results and discussion}

\subsection{Microstructures}

It is known that variation on the processing techniques influences the microstructure of Ti6Al4V alloy. Titanium is known with its two types of crystalline structures, namely a hexagonal close-packed (HCP) structure ( $\alpha$ phase), and a body-centered cubic (BCC) structure ( $\beta$ phase). XRD analysis revealed the existence of both of these phases on all tested samples (Fig. 1), however, some peaks exhibited relatively different intensities between CM, HP, and SLM samples suggesting differences on the content of each phases between each group of samples. Since $\alpha$ and $\alpha^{\prime}$ (martensite) phases both have HCP structure with very similar lattice parameters, as suggested by Facchini et al. (2010) and Sing et al. (2016), the HCP peaks observed on SLM sample can be attributed to both $\alpha$ and $\alpha^{\prime}$ phases.

Commercial cast and forged Ti6Al4V alloy usually presents a finely distributed $\alpha$ phase and a relatively smaller percentage of $\beta$ phase distributed along the grain boundaries of the $\alpha$ phase, as also presented by Karimzadeh et al. (2008) and Rodrigues et al. (2018). These phases were also reported for the HP alloy by Buciumeanu et al. (2017) and Gronostajski et al. (2009), however, with a different morphology, namely a lamellar structure. On the other hand, as mentioned above,

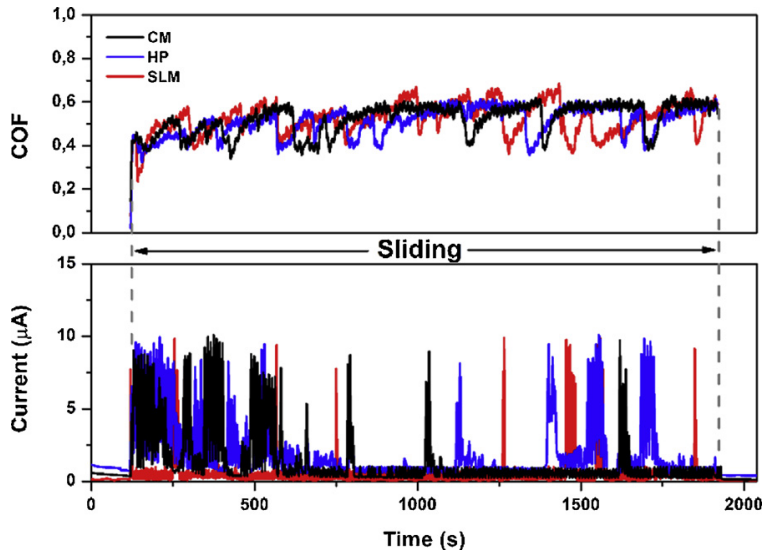

Fig. 6. Evolution of COF and anodic current on tribocorrosion.

high temperature gradients occurring during SLM processing typically results with formation of a fine, acicular $\alpha^{\prime}$ martensite structure that had previously been presented by Kasperovich and Hausmann (2015) and Thijs et al. (2010). As in accordance with the literature, the typical microstructures were observed on as-received CM alloy, as well as on as-processed HP and SLM samples (Fig. 2).

\subsection{Corrosion behaviour}

Fig. 3 gives the OCP evolution during the last $30 \mathrm{~min}$ of immersion together with the representative potentiodynamic polarization curves for each group of samples and Table 1 presents the stabilization OCP values, together with the electrochemical data derived from the potentiodynamic polarization curves. Statistical analysis did not reveal any significant difference on $\mathrm{E}_{\mathrm{OCP}}$ or $\mathrm{E}_{(i=0)}$ values between the testing groups, pointing no significant difference on tendency to corrosion. On the other hand, potentiodynamic polarization curves revealed that CM samples exhibited relatively more stable passivation plateau and slightly lower $i_{\text {pass }}$ values as compared to HP and SLM samples, however, statistical analysis did not reveal a significant difference on $i_{\text {pass }}$ values.

EIS studies were performed to have a further understanding on the influence of the processing route on the corrosion mechanism. Fig. 4 gives the representative EIS spectra recorded for all samples in the form of Bode diagram. All samples exhibited two time-constants on the Bode diagram where the first time-constant was found for medium frequencies, and the second time-constant was present for low frequency ranges, though SLM samples presented relatively lower $|\mathrm{Z}|_{f \rightarrow 0}$ and phase angle values.

Fig. 5 presents the electrical equivalent circuit (EEC) applied for fitting the EIS data for CM, HP, and SLM samples, fitted by Z-View software (version 2.9). The proposed EEC assumes an outer porous layer formed on an inner barrier layer, as had also been used by Fekry and El-Sherif (2009) and Venugopalan et al. (2000) for Ti6Al4V alloy. The EEC contains three resistors being electrolyte resistance $\left(R_{e}\right)$, porous layer resistance $\left(R_{p 1}\right)$, barrier layer resistance $\left(R_{b 1}\right)$, as well, constant phase elements (CPE) representing the non-ideal capacitance of the porous layer $\left(\mathrm{Q}_{\mathrm{pl}}\right)$ and the barrier layer $\left(\mathrm{Q}_{\mathrm{bl}}\right)$. $\mathrm{CPE}$ was involved representing the deviation of ideal capacitor behaviour. The impedance

Table 2

Electrical equivalent circuit parameters.

\begin{tabular}{|c|c|c|c|c|c|c|}
\hline Samples & $\mathrm{Q}_{\mathrm{pl}}\left(\times 10^{-5} \mathrm{~S} \mathrm{~s}^{\mathrm{n}} \mathrm{cm}^{-2}\right)$ & $\mathrm{n}_{\mathrm{pl}}$ & $\mathrm{R}_{\mathrm{pl}}\left(\mathrm{K} \Omega \mathrm{cm}^{2}\right)$ & $\mathrm{Q}_{\mathrm{bl}}\left(\times 10^{-5} \mathrm{~S} \mathrm{~s}^{\mathrm{n}} \mathrm{cm}^{-2}\right)$ & $\mathrm{n}_{\mathrm{bl}}$ & $\mathrm{R}_{\mathrm{bl}}\left(\mathrm{K} \Omega \mathrm{cm}^{2}\right)$ \\
\hline $\mathrm{CM}$ & $2.87 \pm 0.21$ & $0.93 \pm 0.01$ & $307 \pm 221$ & $1.17 \pm 0.19$ & $0.82 \pm 0.06$ & $1087 \pm 805$ \\
\hline HP & $2.33 \pm 0.71$ & $0.92 \pm 0.03$ & $112 \pm 81$ & $0.48 \pm 0.14$ & $0.76 \pm 0.05$ & $1280 \pm 597$ \\
\hline SLM & $5.71 \pm 1.73$ & $0.87 \pm 0.04$ & $0.85 \pm 0.71$ & $5.90 \pm 2.39$ & $0.74 \pm 0.10$ & $506 \pm 63$ \\
\hline
\end{tabular}



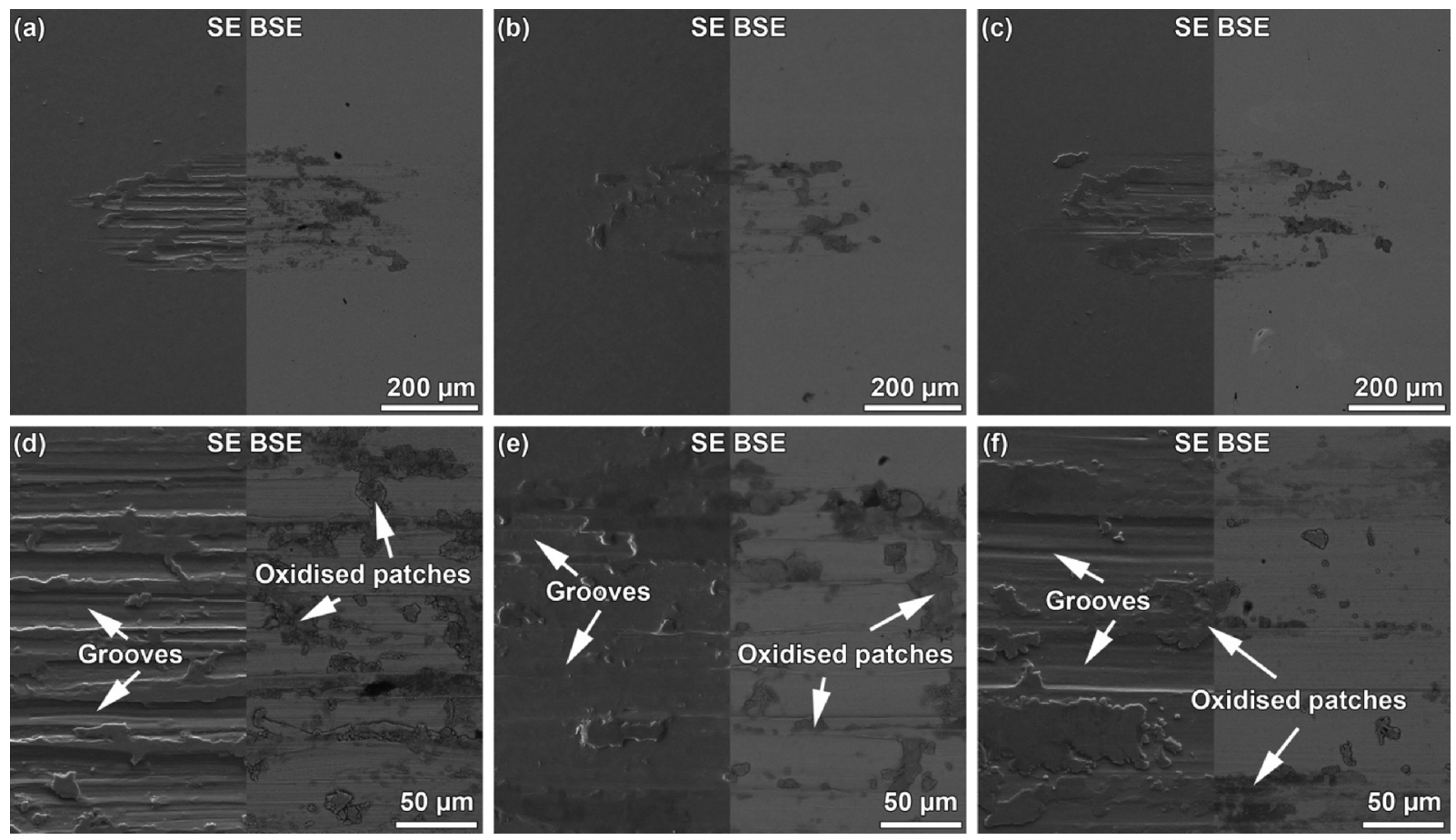

Fig. 7. a, b, c) Lower magnification and d, e, f) higher magnification worn surface SEM images of CM, HP, and SLM samples, respectively.

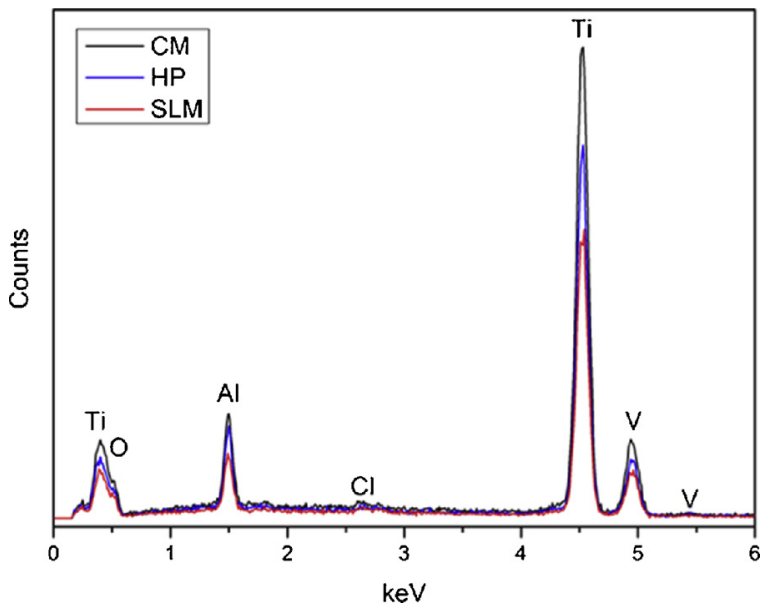

Fig. 8. EDS spectra taken from the worn surfaces.

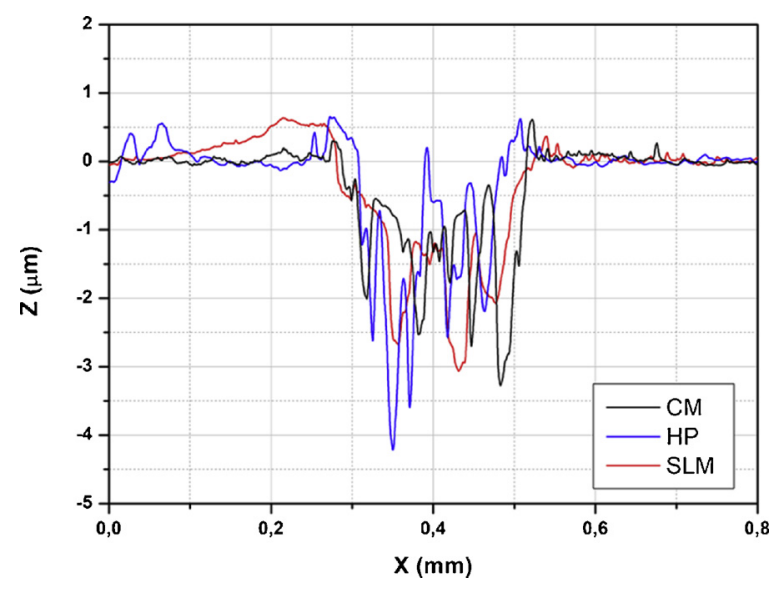

Fig. 9. 2D Wear track profiles.
Table 3

Wear volume loss values.

\begin{tabular}{llll}
\hline Samples & $V_{\text {chem }}\left(\times 10^{-6} \mathrm{~mm}^{3}\right)$ & $V_{\text {mech }}\left(\times 10^{-5} \mathrm{~mm}^{3}\right)$ & $V_{\text {tot }}\left(\times 10^{-5} \mathrm{~mm}^{3}\right)$ \\
\hline CM & $4.96 \pm 2.44$ & $8.65 \pm 3.29$ & $9.15 \pm 3.17$ \\
HP & $5.97 \pm 2.96$ & $13.00 \pm 2.36$ & $13.60 \pm 2.19$ \\
SLM & $6.35 \pm 6.85$ & $12.28 \pm 2.79$ & $12.92 \pm 3.48$ \\
\hline
\end{tabular}

of CPE is defined as $Z_{C P E}=\left[Y_{0}(j w)^{n}\right]^{-1}$, where $Y_{0}$ is a frequency-independent constant, $j=(-1)^{1 / 2}, w$ is the angular frequency, and $n$ is the fractional exponent represents the surface irregularities. When $n \approx 1$, $\mathrm{CPE}$ is considered as a non-ideal capacitor taking into account the effect of roughness and heterogeneities to $n$ values. For all samples, $n_{p l}$ values were obtained between 0.87-0.93 whereas $n_{b l}$ values were between 0.74-0.82. Chi-square $\left(\chi^{2}\right)$ values below $1 \times 10^{-4}$ revealed a good accordance between the EIS data and the fitted values. Table 2 gives the experimental EEC parameters.

Barrier layer resistance $\left(R_{b l}\right)$ was noticeable higher than the porous layer resistance $\left(\mathrm{R}_{\mathrm{pl}}\right)$ for all sample groups, suggesting that for all cases corrosion resistance of the barrier layer was higher as compared to the porous layer. Although SLM samples presented relatively lower values of $R_{p l}$ and $R_{b l}$, as well, relatively lower values of $n_{p l}$ and $n_{b l}, Q_{p l}$ and $Q_{b l}$ were the only cases where statistically significant differences $(p<0.05)$ were obtained, suggesting a relatively lower quality for the porous and barrier layers formed on SLM samples.

Vaithilingam et al. (2016) investigated the surface chemistry of SLM-produced Ti6Al4V after remelting and skin scanning and reported significant differences as compared to the conventional forged alloy. The authors stated that the differences on the oxide film thickness together with the elevated $\mathrm{Al}$ concentration on the surface may influence the electrochemical response. Dai et al. (2016) studied the corrosion behaviour of the SLM-produced Ti6Al4V alloy in $3.5 \mathrm{wt} \% \mathrm{NaCl}$ solution as compared with the commercial Ti6Al4V alloy. The authors reported significantly lower native oxide film resistance values, together with higher $i_{\text {pass }}$ values for SLM-produced alloy as compared to the commercial one. Lower corrosion resistance was attributed to the extensive amount of $\alpha^{\prime}$ phase that defined by the authors as a 'higher 
energy state' in terms of electrochemical response. Accordingly, as presented on the XRD spectra (Fig. 1), the intensity of the BCC peak, representing the $\beta$-phase found as significantly lower on SLM samples, as well, considerable amount of $\alpha^{\prime}$ phase was observed on their microstructures. Therefore, the difference on the corrosion behaviour of SLM samples may be related with the decreased $\beta$ phase and the formation of $\alpha^{\prime}$ phase.

\subsection{Tribocorrosion behaviour}

The representative evolution of the anodic current and coefficient of friction (COF) during tribocorrosion is presented in Fig. 6. As soon as sliding started, a sudden increase on the anodic current values were observed for all groups indicating an increased corrosion kinetics due to the mechanical damage given to the passive film. CM and HP samples exhibited oscillations during approx. first $12 \mathrm{~min}$ of sliding, and after that, the evolution of the anodic current was comparatively stable for both samples. However, SLM samples presented relatively homogenous behaviour during the whole sliding period where narrower current peaks were observed on the graph without accumulating on a certain period of the sliding. As soon as the sliding stopped, the anodic current values dropped to values near the stabilization values obtained before sliding due to the recovery of the passive film. On the other hand, all samples presented similar evolution of the COF, having values oscillating around 0.55 .

Worn surfaces after tribocorrosion exhibited typical features for $\mathrm{Ti}$ and its alloys, namely grooves parallel to sliding direction and oxidised patches (Fig. 7). It is known that adhesive wear is a common wear mechanism on metal/ceramic sliding couples. During sliding action, repetitive transfer of the testing metal can take place between the sliding surfaces. During this transfer, oxidised wear debris or oxidised patches (Fig. 8) may form on the tested surfaces. The oxidised patches or compacted oxidised wear debris, which are harder than the testing metal, can contribute to carry the load and give a limited protection during tribocorrosion. However, in the same time, freely moved oxidised debris can act as extra abrasives (third-body particles) on the sliding surfaces resulting in formation of the grooves and abrasion scratches on the sample surfaces. This twofold effect of the oxidised worn surface features had also been reported by Silva et al. (2017) for $\mathrm{Ti}$ and Toptan et al. (2016) for $\mathrm{Ti}-\mathrm{B}_{4} \mathrm{C}$ composites.

Hardness of the as-processed alloys were measured as $342 \pm 2$, $360 \pm 3$, and $388 \pm 5 \mathrm{HV}_{0.3}$ for $\mathrm{CM}$, HP, and SLM samples, respectively, having statistically significant differences between them $(p<$ $0.05)$. However, the representative $2 \mathrm{D}$ wear track profiles presented on Fig. 9 did not reveal a clear difference. Accordingly, wear volume loss values in terms of $V_{\text {mech }}$, $V_{\text {chem }}$, or $V_{\text {tot }}$ did not reveal any statistically significant differences between the samples, although some differences can be seen on the average values presented on Table 3 .

Runa et al. (2013) considered the ratio between the material loss due to wear-accelerated corrosion and mechanical wear as an indication for the synergistic interactions between corrosion and wear in Ti6Al4V alloy, and suggested that if this ratio is $\leq 0.1$, the degradation mechanism is wear-dominated, whereas if the ratio is $>10$, the degradation mechanism is corrosion-dominated. In the present work, $V_{\text {chem }} / V_{\text {mech }}$ ratios were found as $5.73 \times 10^{-2}, 4.59 \times 10^{-2}$, and $5.17 \times 10^{-2}$ for CM, HP, and SLM samples, respectively. Therefore, according to the criterion that had also been used by Mathew et al. (2011) for corrosion and wear interactions on CoCrMo alloy and by Stack and Abdulrahman (2010) for erosion and corrosion interactions on carbon steel, the degradation mechanism was found as wear-dominated for all tested samples within the testing conditions.

Although mechanical approach is considered as a useful tool to study the interactions between corrosion and wear, as stated by Mischler (2008), it is established with a simplified consideration on the tribocorrosion processes, and it does not take into account the contribution of the wear debris as third body particles, although they can contribute to the current during the repeated mechanical action. Besides, Igual Muñoz and Espallargas (2011) and Mischler (2008) stated that $V_{\text {mech }}$ and $V_{\text {chem }}$ are not independent phenomena, they interact each other during tribocorrosion. During tribocorrosion under an applied anodic potential, the passive film is formed rapidly under the influence of the applied potential, and it is removed by the mechanical action, repeatedly.

After this first comparative insight on the synergistic interactions between corrosion and wear on CM, HP, and SLM Ti6Al4V alloy, further studies should be performed in order to have a further understanding to the degradation mechanism. First, degradation mechanism should be investigated as a function of as normal load and sliding time, being critical testing parameters on tribocorrosion. Second, released metallic ions should be quantified after long time immersion and tribocorrosion. Finally, the tests should be performed in more complex physiological solutions, as well, the contributions of proteins and bioorganisms to the degradation mechanism should be explored.

\section{Conclusions}

Corrosion and tribocorrosion behaviour of Ti6Al4V processed by SLM and HP was investigated in $9 \mathrm{~g} / \mathrm{L} \mathrm{NaCl}$ solution in comparison with the commercial alloy. Electrochemical studies revealed that decreased $\beta$ phase and the formation of $\alpha^{\prime}$ phase affected the electrochemical response of the SLM-produced alloy by leading to a relatively lower quality for the passive film. However, analysis of the synergistic interplay between wear and corrosion showed that total volume loss, volume loss due to mechanical wear, or volume loss due to wear-accelerated corrosion did not show any statistically significant difference between the processing routes.

\section{Acknowledgements}

This study was supported by FCT with the reference project UID/ EEA/04436/2013, by FEDER funds through the COMPETE 2020 Program Operacional Competitividade e Internacionalização (POCI) with the reference project POCI-01-0145-FEDER-006941, together with projects NORTE-01-0145-FEDER-000018-HAMaBICo and PTDC/EMSTEC/5422/2014. The authors would also like to acknowledge Prof. Graça Minas for the provision of the profilometry.

\section{References}

Amaya-Vazquez, M.R., Sánchez-Amaya, J.M., Boukha, Z., Botana, F.J., 2012 Microstructure, microhardness and corrosion resistance of remelted TiG2 and Ti6Al4V by a high power diode laser. Corros. Sci. 56, 36-48. https://doi.org/10. 1016/j.corsci.2011.11.006.

Attar, H., Prashanth, K.G., Chaubey, A.K., Calin, M., Zhang, L.C., Scudino, S., Eckert, J., 2015. Comparison of wear properties of commercially pure titanium prepared by selective laser melting and casting processes. Mater. Lett. 142, 38-41. https://doi. org/10.1016/j.matlet.2014.11.156.

Bartolomeu, F., Faria, S., Carvalho, O., Pinto, E., Alves, N., Silva, F.S., Miranda, G., 2016. Predictive models for physical and mechanical properties of Ti6Al4V produced by Selective Laser Melting. Mater. Sci. Eng. A 663, 181-192. https://doi.org/10.1016/j. msea.2016.03.113.

Bolzoni, L., Meléndez, I.M., Ruiz-Navas, E.M., Gordo, E., 2012. Microstructural evolution and mechanical properties of the Ti-6Al-4V alloy produced by vacuum hot-pressing. Mater. Sci. Eng. A 546, 189-197. https://doi.org/10.1016/j.msea.2012.03.050.

Buciumeanu, M., Araujo, A., Carvalho, O., Miranda, G., Souza, J.C.M., Silva, F.S., Henriques, B., 2017. Study of the tribocorrosion behaviour of Ti6Al4V - HA biocomposites. Tribol. Int. 107, 77-84. https://doi.org/10.1016/j.triboint.2016.11.029.

Dai, N., Zhang, L.-C., Zhang, J., Chen, Q., Wu, M., 2016. Corrosion behavior of selective laser melted Ti-6Al-4V alloy in NaCl solution. Corros. Sci. 102, 484-489. https://doi. org/10.1016/j.corsci.2015.10.041.

de Damborenea, J.J., Arenas, M.A., Larosa, M.A., Jardini, A.L., de Carvalho Zavaglia, C.A., Conde, A., 2017. Corrosion of Ti6Al4V pins produced by direct metal laser sintering. Appl. Surf. Sci. https://doi.org/10.1016/j.apsusc.2016.10.031.

Doni, Z., Alves, A.C., Toptan, F., Gomes, J.R., Ramalho, A., Buciumeanu, M., Palaghian, L., Silva, F.S., 2013. Dry sliding and tribocorrosion behaviour of hot pressed CoCrMo biomedical alloy as compared with the cast CoCrMo and Ti6Al4V alloys. Mater. Des. 52, 47-57. https://doi.org/10.1016/j.matdes.2013.05.032.

Facchini, L., Magalini, E., Robotti, P., Molinari, A., Höges, S., Wissenbach, K., 2010. 
Ductility of a Ti-6Al-4V alloy produced by selective laser melting of prealloyed powders. Rapid Prototyp. J. 16, 450-459. https://doi.org/10.1108/ 13552541011083371.

Fekry, A.M., El-Sherif, R.M., 2009. Electrochemical corrosion behavior of magnesium and titanium alloys in simulated body fluid. Electrochim. Acta 54, 7280-7285. https:// doi.org/10.1016/j.electacta.2009.07.047.

Gronostajski, Z., Bandoła, P., Skubiszewski, T., 2009. Influence of cold and hot pressing on densification behaviour of titanium alloy powder Ti6Al4V. Arch. Civ. Mech. Eng. 9, 47-57. https://doi.org/10.1016/S1644-9665(12)60059-4.

Igual Muñoz, A., Espallargas, N., 2011. Tribocorrosion mechanisms in sliding contacts. Tribocorrosion of Passive Metals and Coatings. Elsevier, pp. 118-152. https://doi. org/10.1016/B978-1-84569-966-6.50005-1.

Karimzadeh, F., Heidarbeigy, M., Saatchi, A., 2008. Effect of heat treatment on corrosion behavior of Ti-6Al-4V alloy weldments. J. Mater. Process. Technol. 206, 388-394. https://doi.org/10.1016/j.jmatprotec.2007.12.065.

Kasperovich, G., Hausmann, J., 2015. Improvement of fatigue resistance and ductility of TiAl6V4 processed by selective laser melting. J. Mater. Process. Technol. 220, 202-214. https://doi.org/10.1016/j.jmatprotec.2015.01.025.

Mathew, M.T., Runa, M.J., Laurent, M., Jacobs, J.J., Rocha, L.A., Wimmer, M.A., 2011. Tribocorrosion behavior of CoCrMo alloy for hip prosthesis as a function of loads: A comparison between two testing systems. Wear. https://doi.org/10.1016/j.wear. 2011.01.086.

Mischler, S., 2008. Triboelectrochemical techniques and interpretation methods in tribocorrosion: A comparative evaluation. Tribol. Int. 41, 573-583. https://doi.org/10. 1016/j.triboint.2007.11.003.

Rodrigues, N.R., Alves, A.C., Toptan, F., Rocha, L.A., 2018. Preliminary investigation on the tribocorrosion behaviour of nanotubular structured Ti6Al4V surfaces. Mater. Lett. 213, 214-217. https://doi.org/10.1016/j.matlet.2017.11.067.

Rooy, E.L., Linden, J.H.L., Van, 1990. ASM Metals Handbook, Vol 02 Properties and Selection: Nonferrous Alloys and Special-Purpose Materials. Metals Park, Ohio. https://doi.org/10.1016/S0026-0576(03)90166-8.

Runa, M.J., Mathew, M.T., Rocha, L.A., 2013. Tribocorrosion response of the Ti6Al4V alloys commonly used in femoral stems. Tribol. Int. 68, 85-93. https://doi.org/10. 1016/j.triboint.2013.09.022.
Silva, J.I., Alves, A.C., Pinto, A.M., Toptan, F., 2017. Corrosion and tribocorrosion behavior of $\mathrm{Ti}-\mathrm{TiB}$ - TiNx in-situ hybrid composite synthesized by reactive hot pressing. J. Mech. Behav. Biomed. Mater 74, 195-203. https://doi.org/10.1016/j. jmbbm.2017.05.041.

Sing, S.L., Yeong, W.Y., Wiria, F.E., 2016. Selective laser melting of titanium alloy with 50 wt $\%$ tantalum: Microstructure and mechanical properties. J. Alloys Compd. 660, 461-470. https://doi.org/10.1016/j.jallcom.2015.11.141.

Stack, M.M., Abdulrahman, G.H., 2010. Mapping erosion-corrosion of carbon steel in oil exploration conditions: Some new approaches to characterizing mechanisms and synergies. Tribol. Int. 43, 1268-1277. https://doi.org/10.1016/j.triboint.2010.01. 005.

Thijs, L., Verhaeghe, F., Craeghs, T., Humbeeck, J. Van, Kruth, J.P., 2010. A study of the microstructural evolution during selective laser melting of Ti-6Al-4V. Acta Mater. 58, 3303-3312. https://doi.org/10.1016/j.actamat.2010.02.004.

Toh, W., Wang, P., Tan, X., Nai, M., Liu, E., Tor, S., 2016. Microstructure and Wear Properties of Electron Beam Melted Ti-6Al-4V Parts: A Comparison Study against AsCast Form. Metals (Basel) 6, 284. https://doi.org/10.3390/met6110284.

Toptan, F., Rego, A., Alves, A.C., Guedes, A., 2016. Corrosion and tribocorrosion behavior of Ti-B4C composite intended for orthopaedic implants. J. Mech. Behav. Biomed. Mater 61, 152-163. https://doi.org/10.1016/j.jmbbm.2016.01.024.

Vaithilingam, J., Goodridge, R.D., Hague, R.J.M., Christie, S.D.R., Edmondson, S., 2016. The effect of laser remelting on the surface chemistry of Ti6Al4V components fabricated by selective laser melting. J. Mater. Process. Technol. 232, 1-8. https://doi. org/10.1016/j.jmatprotec.2016.01.022.

Venugopalan, R., Weimer, J.J., George, M.A., Lucas, L.C., 2000. The effect of nitrogen diffusion hardening on the surface chemistry and scratch resistance of Ti-6Al-4V alloy. Biomaterials 21, 1669-1677. https://doi.org/10.1016/S0142-9612(00) 00049-1.

Vrancken, B., Thijs, L., Kruth, J.P., Van Humbeeck, J., 2012. Heat treatment of Ti6Al4V produced by Selective Laser Melting: Microstructure and mechanical properties. J. Alloys Compd. 541, 177-185. https://doi.org/10.1016/j.jallcom.2012.07.022.

Zhang, L.-C., Attar, H., 2016. Selective Laser Melting of Titanium Alloys and Titanium Matrix Composites for Biomedical Applications: A Review. Adv. Eng. Mater. https:// doi.org/10.1002/adem.201500419. 